\title{
PolyIC Induces Retinoic Acid-inducible Gene-I and Melanoma Differentiation-associated Gene 5 and Modulates Inflammation in Podocytes
}

\author{
MASAMICHI NAKATA ${ }^{1}$, MICHIKO SHIMADA ${ }^{1}$, IKUYO NARITA-KINJO ${ }^{1}$, \\ DAIKI NAGAWA ${ }^{1}$, KAZUTAKA KITAYAMA ${ }^{1}$, MISATO HAMADATE ${ }^{1}$, NAOTAKE MIURA ${ }^{1}$, \\ MASASHI NOZAKA ${ }^{1}$, YOSUKE KAWAMURA ${ }^{1}$, TAKESHI FUJITA ${ }^{1}$, REIICHI MURAKAMI ${ }^{1}$, \\ TADAATSU IMAIZUMI ${ }^{2}$, NORIO NAKAMURA ${ }^{3}$ and HIROFUMI TOMITA ${ }^{1}$ \\ ${ }^{1}$ Department of Cardiology and Nephrology, Hirosaki University Graduate School of Medicine, Hirosaki, Japan; \\ ${ }^{2}$ Department of Vascular Biology, Hirosaki University Graduate School of Medicine, Hirosaki, Japan; \\ ${ }^{3}$ Community Medicine, Hirosaki University Graduate School of Medicine, Hirosaki, Japan
}

\begin{abstract}
Background/Aim: Viral infection often exacerbates proteinuria, which has been suggested to be due to antiviral responses of podocytes. We examined the effect of polyinosinic-polycytidylic acid (polyIC) on the expression of retinoic acid-inducible gene-I (RIG-I) and melanoma differentiation-associated gene 5 (MDA5) in differentiated human podocytes in culture. Materials and Methods: The podocytes were treated with $2 \mathrm{ng} / \mathrm{ml}$ to $500 \mu \mathrm{g} / \mathrm{ml}$ of polyIC for 3 to $36 \mathrm{~h}$, and also transfected with siRNA against RIG$I$ and MDA5. F-actin staining was performed to assess actin reorganization. Results: PolyIC induced the expression of RIG-I and MDA5 in dose- and time-dependent manner, accompanied with interferon- $\beta$ (IFN- $\beta$ ) and interleukin- 6 (IL-6) up-regulation and actin reorganization. Temporal knockdown of RIG-I by siRNA decreased IFN- $\beta$ expression, while MDA5 siRNA inhibited IFN- $\beta$ and IL-6 expression. Actin reorganization was attenuated by RIG-I and MDA5 knockdown. Conclusion: RIG-I and MDA5 may play a role in the antiviral responses of podocytes.
\end{abstract}

Viral infection often causes or exacerbates glomerular diseases, which may be due to immune responses of the intrinsic kidney cells (1). The innate immune system serves as a first-line host defense (2). The pattern recognition

This article is freely accessible online.

Correspondence to: Michiko Shimada, Department of Cardiology and Nephrology, Hirosaki University Graduate School of Medicine, 5 Zaifu-cho, Hirosaki 036-8562, Japan. Tel: +81 172395056, Fax: +81 172359190, e-mail: mshimada@hirosaki-u.ac.jp

Key Words: Podocyte, polyIC, RIG-I, MDA5, innate immunity. receptors (PRRs) recognize pathogen-associated molecular patterns expressed by pathogenic microbes. The PRR family comprises four different classes: Toll-like receptors (TLRs) and C-type lectin receptors, which are transmembrane proteins, and retinoic acid-inducible gene-I (RIG-I)-like receptors (RLRs) and NOD-like receptors, which are cytoplasmic proteins (3). When PRRs recognize microbial components, type I IFN production is induced and nuclear factor-kappa B $(\mathrm{NF}-\mathrm{kB})$ is activated $(2,4)$, leading to inflammatory responses.

Among the PRRs, the expression of TLRs and their role in various kidney diseases have been relatively well explored, for example, TLR7 and TLR9 are involved in lupus nephritis (5), TLR3 and TLR4 in minimal change disease (6), and TLR3 in hepatitis $\mathrm{C}$-associated glomerulonephritis (7). However, there is limited information on the expression of RLRs in the kidney.

The RLR family commonly contains the DExD/H motif, which encodes an RNA helicase, and a C-terminus domain, which recognizes RNA (8). RIG-I preferentially recognizes negative-stranded RNA, including that of influenza viruses and rhabdoviruses, whereas MDA5 recognizes positivestranded RNA, including that of picornaviruses, and relatively long RNA (8).

PolyIC is a synthetic double-stranded RNA (dsRNA), which has been widely used to mimic viral infection. It is recognized by several TLRs as well as RLRs (9). It has been shown to increase RIG-I expression and to up-regulate cytokine and chemokine expression in mesangial cells (10, 11). In glomerular endothelial cells (GEnC), polyIC induces RIG-I expression, along with inflammatory cytokines, chemokines, and type I IFN, and increases GEnC permeability (12). In the present study, we hypothesized that RIG-I and MDA5 expression is induced by polyIC in podocytes, which subsequently leads to podocyte damage. 

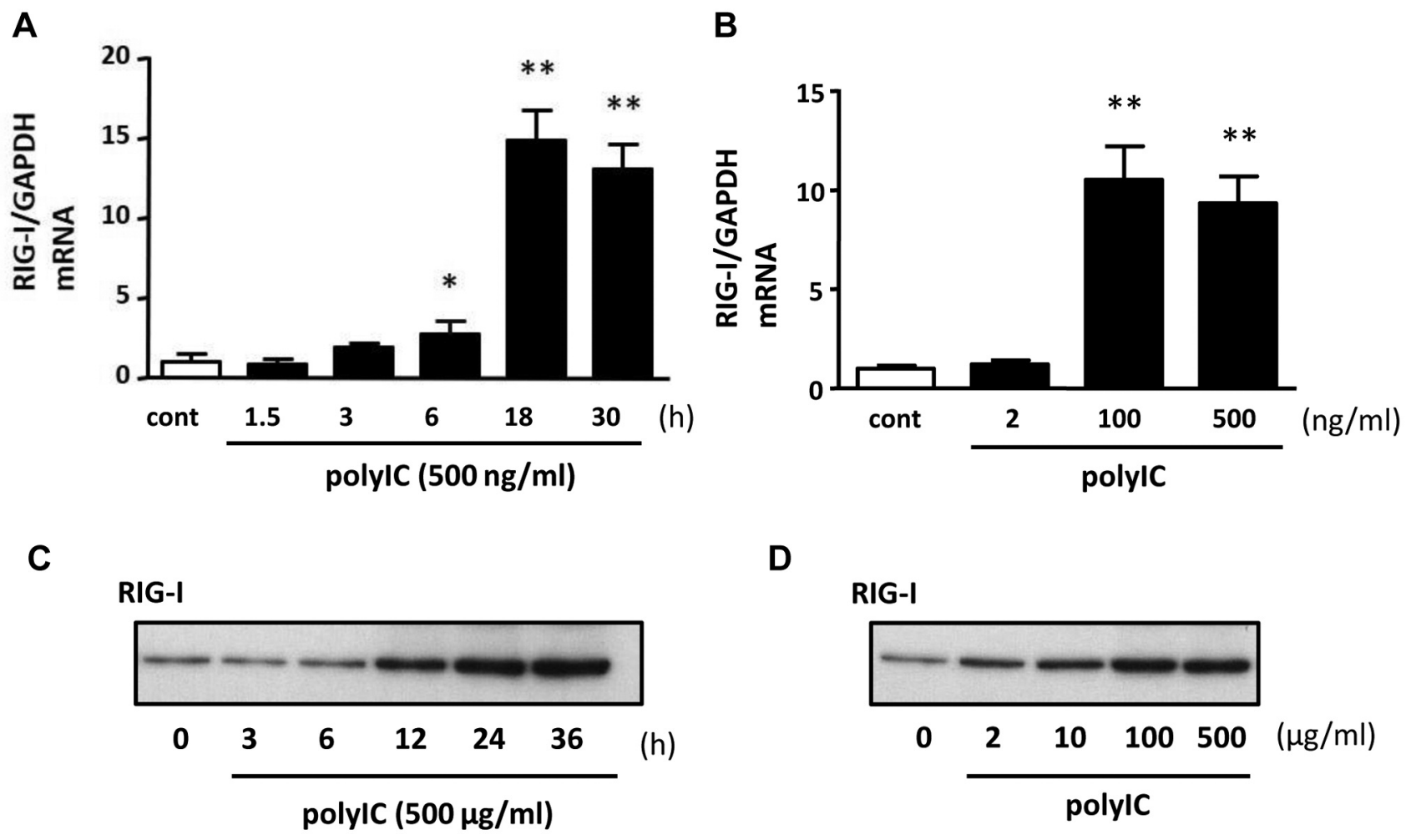

D

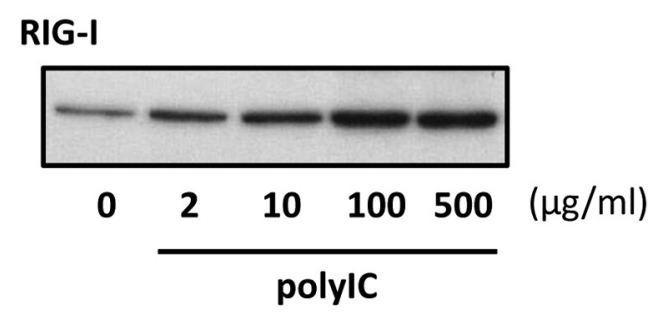

Figure 1. Polyinosinic-polycytidylic acid (PolyIC) induced retinoic acid-inducible gene-I (RIG-I) expression on cultured human podocytes. Quantitative reverse transcription polymerase chain reaction $(q R T-P C R)(A, B)$ and western blot $(C, D)$ analysis showed an increased expression of RIG-I after polyIC treatment. $500 \mathrm{ng} / \mathrm{ml}$ polyIC up-regulated $\mathrm{mRNA}$ of RIG-I (A) and $500 \mu \mathrm{g} / \mathrm{ml}$ PolyIC induced protein of RIG-I (C) in time dependent manner. Similarly, polyIC induced mRNA $(B)$ and protein $(D)$ of RIG-I in dose dependent manner. GAPDH was used as an internal control. The results represent the means $\pm S E M\left(n=3\right.$ wells). ${ }^{*} p<0.05 ; * * p<0.001$ versus control.

\section{Materials and Methods}

Cell culture. Immortalized human podocytes were maintained in RPMI 1640 containing 10\% fetal bovine serum (FBS), $1 \%$ insulintransferrin-selenium-A supplement (Invitrogen, Carlsbad, CA, USA), $100 \mathrm{U} / \mathrm{ml}$ penicillin, and $100 \mu \mathrm{g} / \mathrm{ml}$ streptomycin. Cells were grown at $33^{\circ} \mathrm{C}$ in $95 \%$ air and $5 \% \mathrm{CO}_{2}$, and then were differentiated by incubating at $37^{\circ} \mathrm{C}$ for 10 days. They were kept in $1 \%$ FBS for $24 \mathrm{~h}$, treated with $2 \mathrm{ng} / \mathrm{ml}$ to $500 \mu \mathrm{g} / \mathrm{ml}$ of polyIC for 3 to $36 \mathrm{~h}$, and used between passages 15 and 18 .

Small interfering RNA. Cultured podocytes were transfected with small interfering RNAs (siRNAs) that target RIG-I and MDA5. A siRNA targeted to an irrelevant mRNA served as the nonspecific control. Cells were transfected with $50 \mathrm{nM}$ siRNA in a medium without antibiotics for $24 \mathrm{~h}$ using the Dharmafect transfection reagent (GE Healthcare, Little Chalfont, UK), in accordance with the manufacturer's protocol. Then, the cells were further incubated for $24 \mathrm{~h}$ in the presence or absence of polyIC. Target gene depletion was determined using quantitative reverse transcription polymerase chain reaction (qRT-PCR).

Analysis of mRNA expression by $q R T-P C R$. The QIA shredder and RNeasy Protect Mini Kit (QIAGEN, Valencia, CA, USA) were utilized for total RNA extraction from the cells. RNA was transcribed into the first-strand cDNA with the Omniscript RT kit (QIAGEN) in accordance with the manufacturer's protocol. qRTPCR was performed using an ABI PRISM 7700 Sequence Detector (Applied Biosystems, Foster City, CA, USA) with TaqMan Universal PCR Master Mix (Applied Biosystems). Specific primers and probes (Applied Biosystems) were acquired for human glyceraldehyde-3-phosphatasedehydrogenase (GAPDH) (Assay ID:Hs99999905_m1), RIG-I (Hs00204833_m1), MDA5 (Hs0107 0332_m1), IL-6 (Hs00985638_g1), and IFN- $\beta$ (Hs0107958_s1) detection. Gene expression results were normalized by GAPDH expression levels.

Western blot analysis. Western blot analysis was performed as described in previous reports (13). Briefly, the cells were lysed using Laemmli reducing sample buffer, and then the lysates were subjected to polyacrylamide gel electrophoresis. The proteins were blotted onto polyvinylidene fluoride membranes, which were then blocked and probed with an anti-RIG-I $(1: 10,000)$, anti-MDA5 $(1: 2,000)$, or anti-actin $(1: 3,000)$ antibody. After washing, the membranes were incubated with horseradish peroxidase-conjugated anti-rabbit IgG antibody. A chemiluminescent substrate was used for detection. 


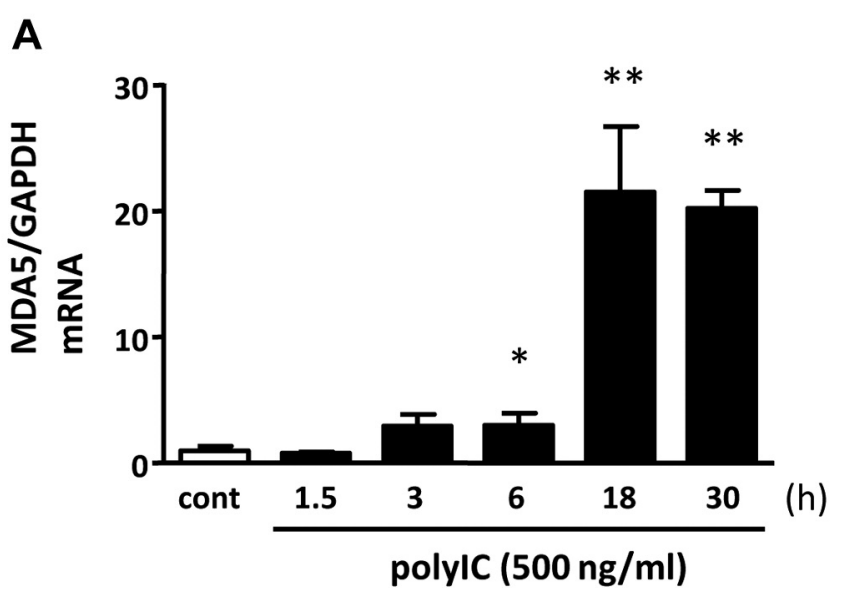

C

\section{MDA5}

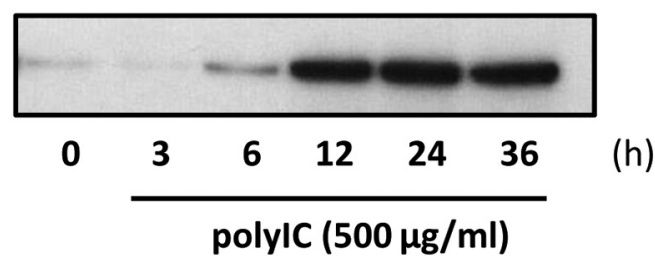

B

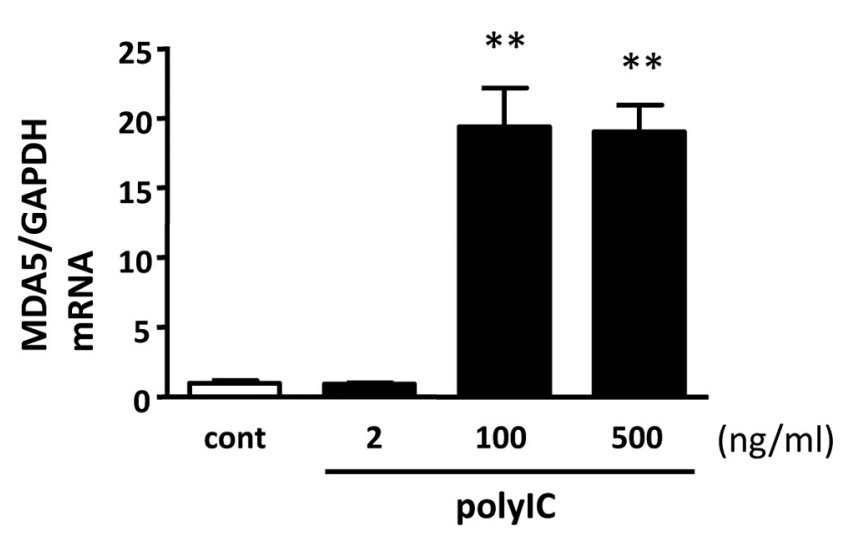

D

\section{MDA5}

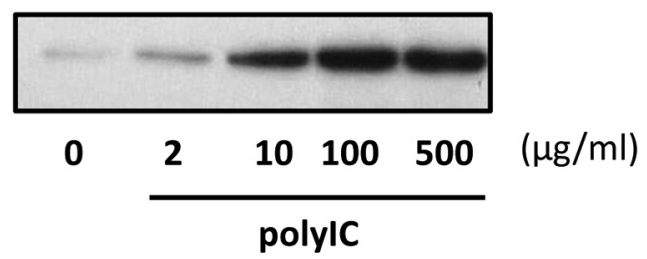

Figure 2. PolyIC induced melanoma differentiation-associated gene 5 (MDA5) expression on cultured human podocytes. qRT-PCR (A, B) and western blot $(C, D)$ analysis showed an increased expression of MDA5 after polyIC treatment. Five hundred ng/ml polyIC up-regulated mRNA of MDA5 (A) and $500 \mu \mathrm{g} / \mathrm{ml}$ PolyIC induced protein of MDA5 $(C)$ in a time-dependent manner. Similarly, polyIC induced mRNA (B) and protein $(D)$ of MDA5 in dose dependent manner. GAPDH was used as an internal control. The results represent the means $\pm S E M(n=3$ wells $) .{ }^{*} p<0.05 ;{ }^{* *} p<0.001$ versus control.

Immunofluorescence study. Glass-bottom culture dishes (MatTec, Ashland, MA, USA) were utilized for podocyte growth and differentiation. Cells were pretreated with $1 \%$ reduced serum for 24 $\mathrm{h}$ and incubated in the presence of polyIC for another $24 \mathrm{~h}$. Then, they were fixed with $4 \%$ paraformaldehyde for $30 \mathrm{~min}$ and permeabilized with $0.1 \%$ Triton X-100 in phosphate-buffered saline for $10 \mathrm{~min}$. For F-actin staining, cells were subjected to fixation and incubated with an Alexa Fluor 488-conjugated phalloidin (1:500) (Molecular Probes, Carlsbad, CA, USA) for $1 \mathrm{~h}$ and imaged using a fluorescence microscope (model BZ-X700; Keyence).

Statistical analysis. All data were expressed as mean \pm standard deviation, which were then compared using Student's independent sample $t$-test or one-way analysis of variance (ANOVA), followed by Tukey's honestly significant difference test and two-way repeated measures ANOVA. $p<0.05$ was considered statistically significant.

\section{Results}

RIG-I expression after treatment with polyIC. To examine the effect of polyIC on human podocytes, we performed qRT-PCR (Figure 1A and B) and western blot (Figure 1C and D) analyses. The RIG-I mRNA expression levels started increasing at $6 \mathrm{~h}$ and were significantly elevated at $18 \mathrm{~h}$ (Figure 1A) of treatment with polyIC (500 ng/ml). In the dose-response experiment, RIGI mRNA expression levels were increased following treatment with $100 \mathrm{ng} / \mathrm{ml}$ polyIC and remained high after $500 \mathrm{ng} / \mathrm{ml}$ polyIC treatment (Figure 1B). RIG-I protein expression levels increased after polyIC treatment in a time- $(500 \mu \mathrm{g} / \mathrm{ml}$, Figure 1C) and dose (Figure 1D)-dependent manner.

The expression of MDA5 after treatment with PolyIC. Next, we analyzed the expression of MDA5 in podocytes treated with polyIC (Figure 2). Gene expression levels increased following treatment with $500 \mathrm{ng} / \mathrm{ml}$ polyIC treatment for $18 \mathrm{~h}$ (Figure 2A), and by $100 \mathrm{ng} / \mathrm{ml}$ polyIC (Figure 2B). PolyIC upregulated the protein levels of MDA-5 in a time $(500 \mu \mathrm{g} / \mathrm{ml}$, Figure 2C) and dose (Figure 2D)-dependent manner.

The expression of inflammatory cytokines after treatment with PolyIC. Increased expression of RIG-I and MDA5 leads to up-regulation of transcription factors, including NF-kB, which promotes the production of inflammatory cytokines. Therefore, we examined whether polyIC induces the gene expression of inflammatory cytokines such as IFN- $\beta$ and IL6. Treatment of differentiated podocytes with $500 \mathrm{ng} / \mathrm{ml}$ 

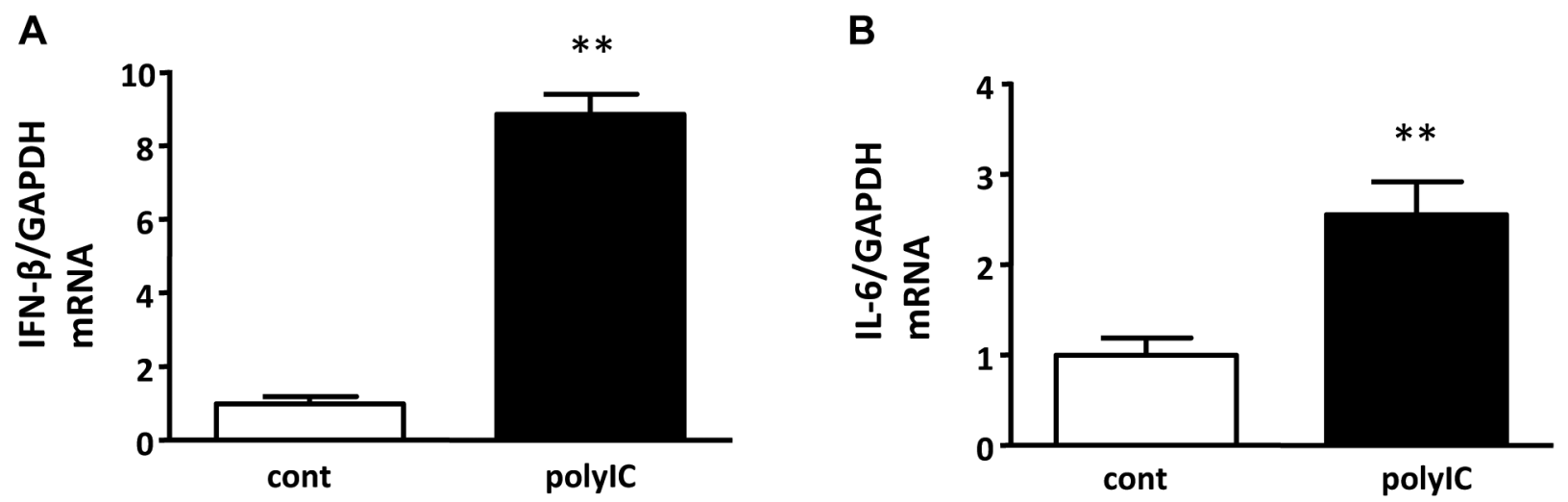

Figure 3. polyIC increased the gene expression of inflammatory cytokines. Cultured human podocytes were treated with $500 \mathrm{ng} / \mathrm{ml}$ polyIC for $6 \mathrm{~h}$. qRT-PCR analysis showed that the gene expression levels of interferon - $\beta(I F N-\beta)(A)$ and interleukin-6 (IL-6) (B) were increased by polyIC treatment. GAPDH was used as an internal control. The results represent the means \pm SEM $(n=3$ wells). * $p<0.05 ; * * p<0.001$ versus control.
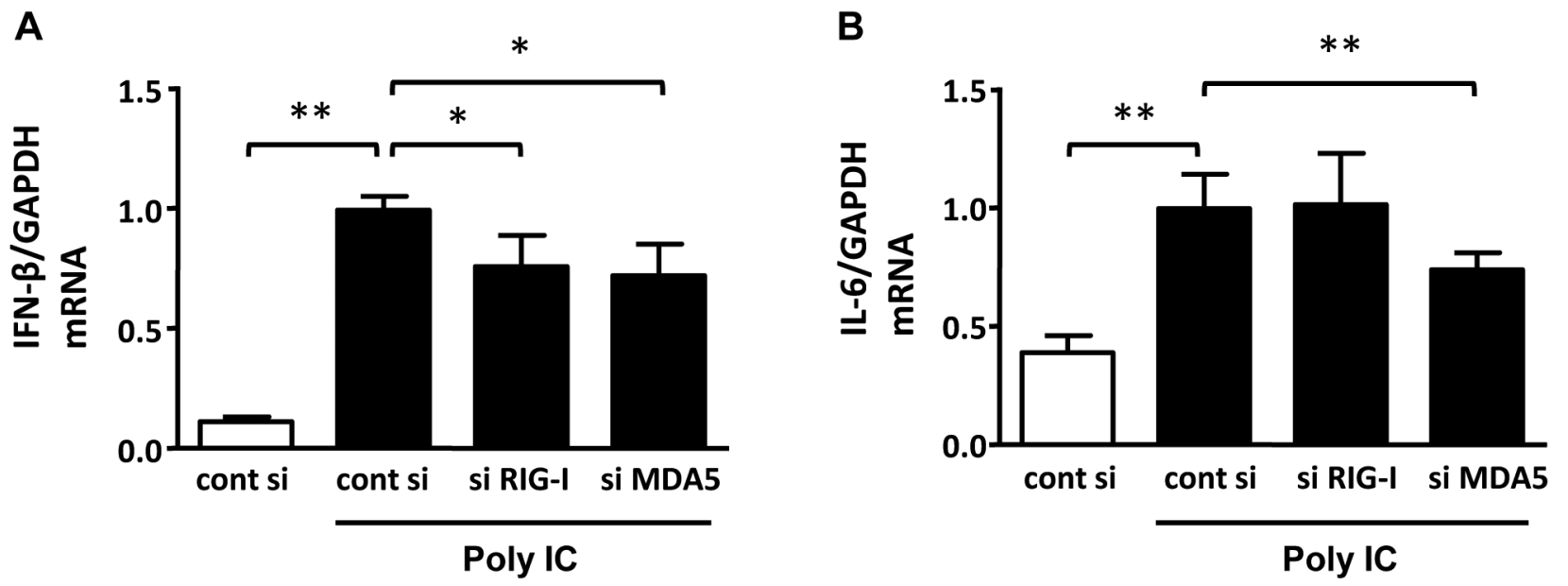

Figure 4. Knockdown of RIG-I and MDA5 with siRNA inhibited the expression of inflammatory cytokines by polyIC. Cultured human podocytes were transfected with non-targeting (control) siRNA, RIG-I, and MDA5 siRNA using Dharmafect Reagent ${ }^{\circledR}$. PolyIC (500 ng/ml) was added and incubated for 6 h. qRT-PCR analysis showed the gene expression levels of IFN- $\beta$ (A) and IL-6 (B). GAPDH was used as an internal control. The results represent the means \pm SEM ( $n=3$ wells). $* p<0.05 ; * * p<0.001$.

polyIC for $6 \mathrm{~h}$ increased the mRNA expression of IFN- $\beta$ and IL-6 (Figures 3A and B).

Effect of small interfering RNA of RIG-I and MDA5. To assess the effect of RLR signaling pathway, we used siRNA to silence RIG-I and MDA5. The gene expression of IFN- $\beta$ was partially but significantly decreased by knockdown of RIG-I and MDA5 (Figure 4A). However, IL-6 expression was partially suppressed by the knockdown of MDA5 but not of RIG-I (Figure 4B).

PolyIC-induced actin reorganization was partially attenuated by RIG-I and MDA5 knockdown. An intact actin cytoskeleton is essential for maintaining the normal shape and function of podocytes. Actin reorganization, histologically observed as foot process effacement, is associated with proteinuria. Differentiated human podocytes have characteristic central stress fibers composed of actin filaments (Figure 5A). PolyIC treatment induced the disruption of actin cytoskeleton (Figure $5 \mathrm{~B}$ ), which was partly attenuated by the temporal knockdown of RIG-I and MDA5 by siRNA (Figures $5 \mathrm{C}$ and D).

\section{Discussion}

Viral infection often causes or exacerbates glomerular diseases. In some cases, host-derived antiviral antibodies have been suggested as the mechanism of the pathogenesis; however, a 
A Poly IC (-), cont si

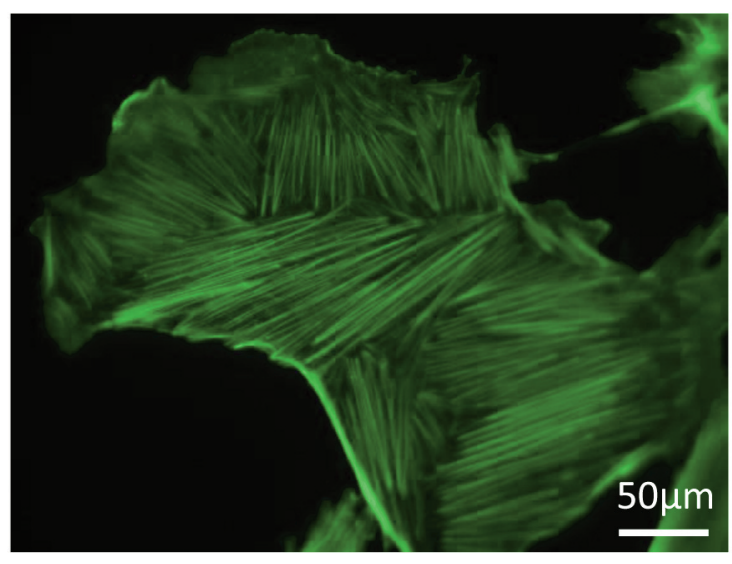

C

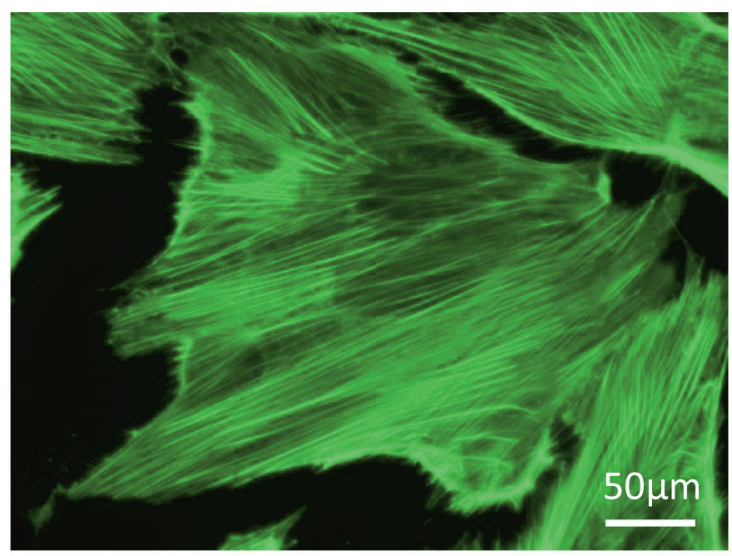

B Poly IC (+), cont si

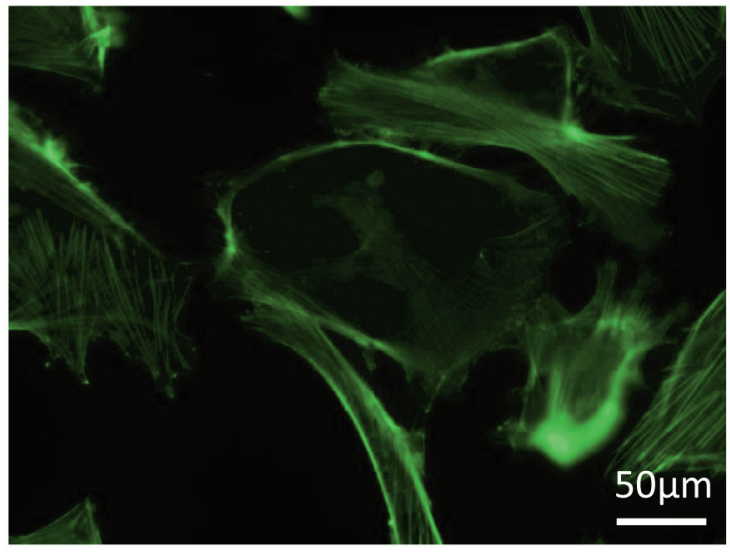

D Poly IC (+), si MDA5

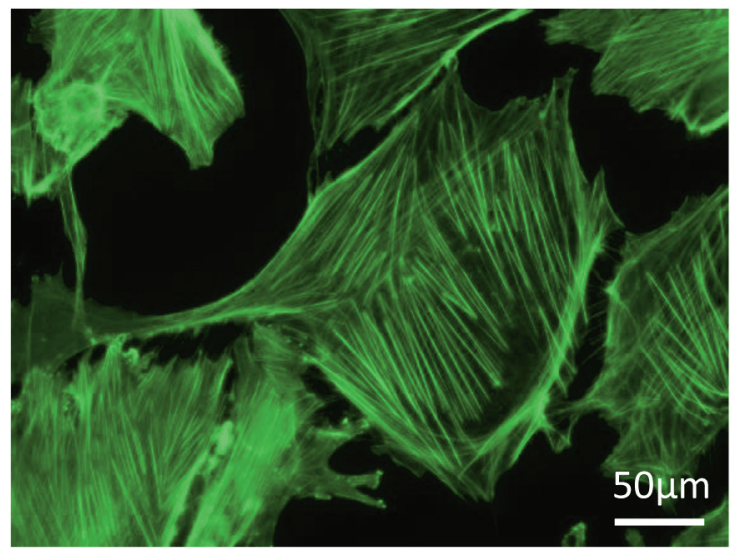

Figure 5. PolyIC-induced actin reorganization was partially attenuated by RIG-I and MDA5 knockdown. F-actin representative microscopic images in human podocytes. Podocytes were transfected with non-targeting siRNA (cont si), RIG-I siRNA, or MDA5 siRNA, followed by treatment with 500 ng/ml poly IC for $24 \mathrm{~h}$. At $72 \mathrm{~h}$ post-transfection, podocytes were fixed and stained with phalloidin to detect F-actin. Magnification $400 \times$. Bar represents 50 um.

direct cytopathogenic effect on glomerular cells has been suggested in HIV-associated focal segmental glomerulosclerosis (1). Besides, in steroid-responsive nephrotic syndrome, at least $50 \%$ of relapses are triggered by viral upper respiratory tract infections (1), suggesting a direct effect of viral infection on podocyte damage.

The role of innate immunity in podocyte damage has been previously investigated $(4,14)$. Lipopolysaccharide (LPS), a TLR4 ligand, has been shown to induce proteinuria and podocyte damage (14). Furthermore, LPS and polyIC, both of which are also TLR3 ligands, induce CD80 expression in podocytes $(4,15)$. It has been reported that urinary CD80 was increased in minimal change disease (16). However, urinary CD80 is not available for the clinical diagnosis of minimal change disease.

Previous reports have shown that polyIC induces the upregulation of inflammatory cytokines and podocyte actin reorganization, which is dependent on CD80 (4). Furthermore, polyIC has been shown to induce transient proteinuria and glomerular CD80 production in mice (15), indicating that innate immunity activation via PRRs is closely related to proteinuria. In the present study, we showed that polyIC induces RIG-I and MDA5 expression. Moreover, the polyIC-induced increase in IL- 6 was RIG-Idependent, and the increase in IFN- $\beta$ levels and actin reorganization were both RIG-I- and MDA5-dependent. Consistently, Flür et al. have reported that in mesangial cells, polyIC-induced IL-6 expression was inhibited by knockdown of MDA5, but not by knockdown of RIG-I (11).

The actin cytoskeleton is essential for the normal function of podocytes. The reorganization of actin cytoskeleton in podocytes is generally accepted as podocyte damage, leading to foot process effacement, which is commonly observed in many proteinuric conditions (17). In macrophages, a 
relationship between RIG-I and actin cytoskeleton has been suggested. RIG-I accumulated in membrane ruffles, clearly colocalizing with F-actin (18). In our study, polyIC-induced actin reorganization was reduced by the knockdown of both RIG-I and MDA5. RIG-I may have a direct and significant role in the pathogenesis of actin reorganization; presumably, multiple mechanisms exist in the pathogenesis of actin reorganization, and RIG-I and MDA5 play a significant role at least in part.

There are some limitations in our study. First, this is an in vitro study. During a viral infection, many systemic reactions and direct cytopathogenic actions occur in the kidney. Our study only focused on podocytes. In addition, phalloidin staining is a generally accepted method for podocyte injury; however, it lacks objectivity and quantitativity. Secondly, we tested only some of the numerous changes occurring upon stimulation with polyIC. Besides, we did not investigate the interplay between TLRs and RLRs nor the interplay between RIG-I and MDA5 in this study. Our results warrant the importance of further studies on the role of RIG-I and MDA5 in podocytes.

In conclusion, our study showed that polyIC remarkably increased the expression of RIG-I and MDA5 in differentiated human podocytes in culture. PolyIC induced the up-regulation of inflammatory cytokines and podocyte actin reorganization, which were partly attenuated by the temporal knockdown of RIG-I and MDA5, suggesting a possible role of RIG-I and MDA5 in the antiviral responses of podocytes.

\section{Conflicts of Interest}

The Authors have no conflicts of interest directly relevant to the content of this article.

\section{Authors' Contributions}

M.S. and T.I conceived of the presented idea. M.N., I.N., M.S., T.I., D.N., K.K., M.H., N.M., M.N., Y.K., T.F. and R.M. carried out the experiments and performed the analytic calculations. N.N. and H.T. helped supervise the project. M.N., I.N. and M.S. wrote the manuscript. All Authors approved the final manuscript.

\section{Acknowledgements}

The Authors would like to thank Prof. Moin A Saleem, University of Bristol, UK for kindly providing human podocytes. The Authors also thank Yoshiko Shutto-Uchita for her excellent technical support.

\section{References}

1 Lai AS and Lai KN: Viral nephropathy. Nat Clin Pract Nephrol 2(5): 254-262, 2006. PMID: 16932438. DOI: 10.1038/ncpneph0166

2 Akira S, Uematsu S and Takeuchi O: Pathogen recognition and innate immunity. Cell 124(4): 783-801, 2006. PMID: 16497588. DOI: $10.1016 /$ j.cell.2006.02.015
3 Takeuchi $\mathrm{O}$ and Akira S: Pattern recognition receptors and inflammation. Cell 140(6): 805-820, 2010. PMID: 20303872. DOI: $10.1016 /$ j.cell.2010.01.022

4 Shimada M, Ishimoto T, Lee PY, Lanaspa MA, Rivard CJ, Roncal-Jimenez CA, Wymer DT, Yamabe H, Mathieson PW, Saleem MA, Garin EH and Johnson RJ: Toll-like receptor 3 ligands induce cd80 expression in human podocytes via an nfkappab-dependent pathway. Nephrol Dial Transplant 27(1): 8189, 2012. PMID: 21617192. DOI: 10.1093/ndt/gfr271

5 Barrat FJ, Meeker T, Chan JH, Guiducci C and Coffman RL: Treatment of lupus-prone mice with a dual inhibitor of tlr7 and tlr9 leads to reduction of autoantibody production and amelioration of disease symptoms. Eur J Immunol 37(12): 35823586, 2007. PMID: 18034431. DOI: 10.1002/eji.200737815

6 Mishra OP, Kumar R, Narayan G, Srivastava P, Abhinay A, Prasad R, Singh A and Batra VV: Toll-like receptor 3 (tlr-3), tlr4 and cd80 expression in peripheral blood mononuclear cells and urinary cd80 levels in children with idiopathic nephrotic syndrome. Pediatr Nephrol 32(8): 1355-1361, 2017. PMID: 28210837. DOI: $10.1007 / \mathrm{s} 00467-017-3613-8$

7 Wornle M, Schmid H, Banas B, Merkle M, Henger A, Roeder M, Blattner S, Bock E, Kretzler M, Grone HJ and Schlondorff D: Novel role of toll-like receptor 3 in hepatitis c-associated glomerulonephritis. Am J Pathol 168(2): 370-385, 2006. PMID: 16436653. DOI: 10.2353 /ajpath.2006.050491

8 Brisse M and Ly H: Comparative structure and function analysis of the rig-i-like receptors: Rig-i and mda5. Front Immunol 10: 1586, 2019. PMID: 31379819. DOI: 10.3389/fimmu.2019.01586

9 Kawai T and Akira S: Toll-like receptors and their crosstalk with other innate receptors in infection and immunity. Immunity 34(5): 637-650, 2011. PMID: 21616434. DOI: 10.1016/j.immuni.2011. 05.006

10 Imaizumi T, Tanaka H, Matsumiya $\mathrm{T}$, Yoshida $\mathrm{H}$, Tanji $\mathrm{K}$, Tsuruga K, Oki E, Aizawa-Yashiro T, Ito E and Satoh K: Retinoic acid-inducible gene-i is induced by double-stranded rna and regulates the expression of cc chemokine ligand (ccl) 5 in human mesangial cells. Nephrol Dial Transplant 25(11): 35343539, 2010. PMID: 20484300. DOI: 10.1093/ndt/gfq270

11 Flur K, Allam R, Zecher D, Kulkarni OP, Lichtnekert J, Schwarz M, Beutler B, Vielhauer V and Anders HJ: Viral rna induces type $\mathrm{i}$ interferon-dependent cytokine release and cell death in mesangial cells via melanoma-differentiation-associated gene-5: Implications for viral infection-associated glomerulonephritis. Am J Pathol 175(5): 2014-2022, 2009. PMID: 19850889. DOI: 10.2353/ajpath.2009.080585

12 Hagele H, Allam R, Pawar RD and Anders HJ: Double-stranded rna activates type i interferon secretion in glomerular endothelial cells via retinoic acid-inducible gene (rig)-1. Nephrol Dial Transplant 24(11): 3312-3318, 2009. PMID: 19608629. DOI: 10.1093/ndt/gfp339

13 Imaizumi T, Aizawa-Yashiro T, Watanabe S, Matsumiya T, Yoshida H, Tatsuta T, Xing F, Meng P, Hayakari R, Tsuruga K and Tanaka H: Tlr4 signaling induces retinoic acid-inducible gene- $i$ and melanoma differentiation-associated gene 5 in mesangial cells. J Nephrol 26(5): 886-893, 2013. PMID: 23559071. DOI: $10.5301 /$ jn.5000254

14 Reiser J, von Gersdorff G, Loos M, Oh J, Asanuma K, Giardino L, Rastaldi MP, Calvaresi N, Watanabe H, Schwarz K, Faul C, Kretzler M, Davidson A, Sugimoto H, Kalluri R, Sharpe AH, Kreidberg JA and Mundel P: Induction of b7-1 in podocytes is 
associated with nephrotic syndrome. J Clin Invest 113(10): 13901397, 2004. PMID: 15146236. DOI: 10.1172/JCI20402

15 Ishimoto T, Shimada M, Gabriela G, Kosugi T, Sato W, Lee PY, Lanaspa MA, Rivard C, Maruyama S, Garin EH and Johnson RJ: Toll-like receptor 3 ligand, polyic, induces proteinuria and glomerular cd80, and increases urinary cd80 in mice. Nephrol Dial Transplant 28(6): 1439-1446, 2013. PMID: 23262434. DOI: $10.1093 / \mathrm{ndt} / \mathrm{gfs} 543$

16 Garin EH, Diaz LN, Mu W, Wasserfall C, Araya C, Segal M and Johnson RJ: Urinary cd 80 excretion increases in idiopathic minimal-change disease. J Am Soc Nephrol 20(2): 260-266, 2009. PMID: 19056875. DOI: 10.1681/ASN.2007080836

17 Mundel P and Reiser J: Proteinuria: An enzymatic disease of the podocyte? Kidney Int 77(7): 571-580, 2010. PMID: 19924101. DOI: $10.1038 / \mathrm{ki} .2009 .424$
18 Kong L, Sun L, Zhang H, Liu Q, Liu Y, Qin L, Shi G, Hu JH, Xu A, Sun YP, Li D, Shi YF, Zang JW, Zhu J, Chen Z, Wang $\mathrm{ZG}$ and Ge BX: An essential role for rig-i in toll-like receptorstimulated phagocytosis. Cell Host Microbe 6(2): 150-161, 2009. PMID: 19683681. DOI: 10.1016/j.chom.2009.06.008

Received September 30, 2020

Revised October 12, 2020

Accepted October 13, 2020 